\title{
Differences between referred and nonreferred patients in cancer research
}

\author{
Jason Faulds, MD* \\ Colleen E. McGahan, $\mathrm{MSc}^{* \dagger}$ \\ P.T. Phang, MD* \\ Manoj J. Raval, MD, MSc* \\ Carl J. Brown, MD, MSc ${ }^{*}$ \\ From the *Department of Surgery, \\ St. Paul's Hospital and University of \\ British Columbia, the tSurgical \\ Oncology Network, BC Cancer Agency, \\ and $¥$ Cancer Surveillance \& Outcomes, \\ BC Cancer Agency, Vancouver, BC
}

Accepted for publication

June 25, 2012

Correspondence to:

C.J. Brown

1081 Burrard St.

Vancouver BC V6Z 1Y6

cbrown@providencehealth.bc.ca

DOI: $10.1503 /$ cjs.027511

\begin{abstract}
Background: In Canada, provincial cancer registries have been established to provide rigorous population-based data for patients with colorectal cancer. Databases maintained by regional cancer agencies contain a broader scope of information and have been used as a surrogate source of information for colorectal cancer research. It is unclear whether these data can be reliably extrapolated to all patients affected by colorectal cancer. We sought to determine whether patients included in a referral-based database are systematically different from patients who are not included.
\end{abstract}

Methods: We conducted a retrospective cohort study to compare patients referred to the British Columbia Cancer Agency with those who were not referred. Comparison was based on age, sex and geographic location. We used univariate and logistic regression analysis to identify significant differences between the cohorts.

Results: Univariate analysis demonstrated that the referral and nonreferral cohorts differed in sex, age and geographic location. For patients with rectal cancer, the referral and nonreferral cohorts varied in age and geographic location. Multivariate analysis demonstrated significant differences in age and geographic location but not sex for patients with colon and rectal cancer.

Conclusion: Patients included in the referral database differed in age and geographic location from those included only in the provincial database. Studies using large data sets from referral centres must be interpreted with caution and may not be representative of the entire patient population.

Background : Au Canada, on a établi des registres provinciaux en oncologie pour générer des données représentatives rigoureuses au sujet des patients atteints de cancer colorectal. Les bases de données maintenues par les agences régionales du cancer contiennent un éventail plus large de renseignements et ont servi de source de données de substitution pour la recherche sur le cancer colorectal. Or, on ignore s'il est possible d'extrapoler ces données de manière fiable à tous les patients atteints de cancer colorectal. Nous avons voulu déterminer si les patients inclus dans une base de données de référence sont systématiquement différents des patients qui n'y figurent pas.

Méthodes : Nous avons procédé à une étude de cohorte rétrospective pour comparer les patients référés à l'agence de lutte contre le cancer de la Colombie-Britannique à ceux qui n'y avaient pas été référés. La comparaison reposait sur l'âge, le sexe et l'emplacement géographique. Nous avons utilisé une analyse de régression univariée et logistique pour dégager les différences significatives entre les cohortes.

Résultats : L'analyse univariée a démontré que les cohortes référée et non référée différaient aux plans du sexe, de l'âge et de l'emplacement géographique. Pour les patients atteints d'un cancer rectal, les cohortes référée et non référée variaient selon l'âge et l'emplacement géographique. L'analyse multivariée a révélé des différences significatives aux plans de l'âge et de l'emplacement géographique, mais non au plan du sexe en ce qui concerne les patients atteints de cancer du côlon et du rectum.

Conclusion : Les patients inclus dans la base de données de référence étaient différents de ceux qui ne figuraient que dans la base de données provinciale, pour ce qui est de l'âge et de l'emplacement géographique. Il faut interpréter avec prudence les études reposant sur d'importantes séries de données provenant de centres de référence, car elles pourraient ne pas être représentatives de toute la population de patients.

olorectal cancer is a leading cause of cancer-related death in North America. ${ }^{1,2}$ Worldwide, the annual incidence of colorectal cancer has been estimated at 780000 to 1 million cases, of which about 20000 cases will be diagnosed in Canada. ${ }^{2-4}$ To monitor the burden of colorectal 
cancer on population health, provincial cancer registries have been established. ${ }^{5}$

To best treat patients with cancer, specialized cancer centres are established in most jurisdictions. In British Columbia, branches of the British Columbia Cancer Agency (BCCA) are the sole providers of radiotherapy and a major provider of chemotherapy for citizens of the province. Research based at these cancer centres is often used to guide cancer treatment for all patients with cancer based on the assumption that the data can be extrapolated to all patients. However, it is unclear whether these data can be used as a substitute for population-based cancer registries owing to health care access bias. ${ }^{6}$ The primary goal of the present study was to determine whether patients with colorectal cancer who are referred to the BCCA are systematically different from those who are not referred and are therefore not captured within the cancer agency database.

\section{Methods}

\section{Cancer databases in British Columbia}

In British Columbia, a registry of all patients with a confirmed tissue diagnosis of cancer is maintained by the British Columbia Cancer Registry (BCCR) and is mandated by provincial law. The scope of data contained within the registry is limited, and no stage-specific data are recorded. To address this, the BCCA established the Gastrointestinal Cancer Outcomes Unit in 2002. This unit maintains a colorectal cancer outcomes database (CRC database), which captures additional disease information, including stage, and treatment information for all patients with colorectal cancer who have been referred to the BCCA. The CRC database has been used in previous cancer outcome research and has been considered a reasonable approximation of population-based data. ${ }^{7-10}$

\section{Data set comparison}

We obtained institutional ethics review board approval from the BCCA. We queried the BCCR to identify all patients in the province with colon, rectosigmoid and rectal cancer diagnosed between January 2002 and December 2004. Patients included in the BCCR represent the entire population of patients with colorectal cancer in British Columbia during the study period. The CRC database solely captures data for patients who have been referred to and used the BCCA. Cross-referencing the BCCR and CRC databases formed a cohort of patients who had used the BCCA (the referred cohort) and a second cohort of patients who had not used the BCCA (nonreferred cohort).

We collected demographic information, including age, sex and regional health authority (representing geographic region within British Columbia), for all patients in each cohort. All adult patients who were residents of British Columbia at the time of colorectal cancer diagnosis were included in the study. Patients who were identified as having rectosigmoid cancer were grouped with patients with colon cancer for the analysis. The rationale for combining patients with rectosigmoid and colon cancer was that these 2 groups of patients were most frequently treated with surgery and chemotherapy and rarely received radiation therapy, suggesting these were not true rectal cancers. We determined and compared rates of chemotherapy between cohorts by reviewing the records of the BCCA pharmacy, which maintains a record of all chemotherapy administered within the province.

\section{Statistical analysis}

We initially recorded data in contingency tables and performed univariate analysis. Statistical analysis involved Student $t$ tests to compare continuous variables and the $\chi^{2}$ test to assess categorical variables. We considered a 2 sided $p$ value of 0.05 to be statistically significant for all comparisons. To account for confounding between variables, we performed logistic regression analysis. The covariates selected for analysis were limited to those for which data were available from both the provincial cancer registry and the Gastrointestinal Cancer Outcomes Unit. Age at diagnosis, sex and regional health authority were the only covariates for which comparative data were available. Age was entered as a continuous variable, whereas sex and health authority were analyzed as categorical variables. We used regression coefficients to determine the odds ratio for capture in the CRC database for each covariate entered in the model.

\section{Results}

We identified 7305 cases of colorectal carcinoma diagnosed between 2002 and 2004 in the BCCR. There were 6749 cases of colorectal adenocarcinoma that met the inclusion criteria and were included in the analysis. The referred cohort comprised 3651 patients from the BCCR who had used the BCCA. The remaining 3098 patients from the BCCR had not used the BCCA and were not in the CRC database, thus forming the nonreferred cohort (Fig. 1).

There were 4940 patients with colon cancer diagnosed during the years of the study. Overall, we included 2302 (46.6\%) patients with colon cancer in the referred cohort and $2638(53.4 \%)$ in the nonreferred cohort. A total of 1809 patients with rectal cancer were identified, with 1349 $(74.6 \%)$ in the referred and $460(25.4 \%)$ in the nonreferred cohorts.

For patients with colon cancer, univariate analysis demonstrated significant differences in sex, age and geographic location. As demonstrated in Table 1, 1071 (44.8\%) women with colon cancer were referred to the BCCA 


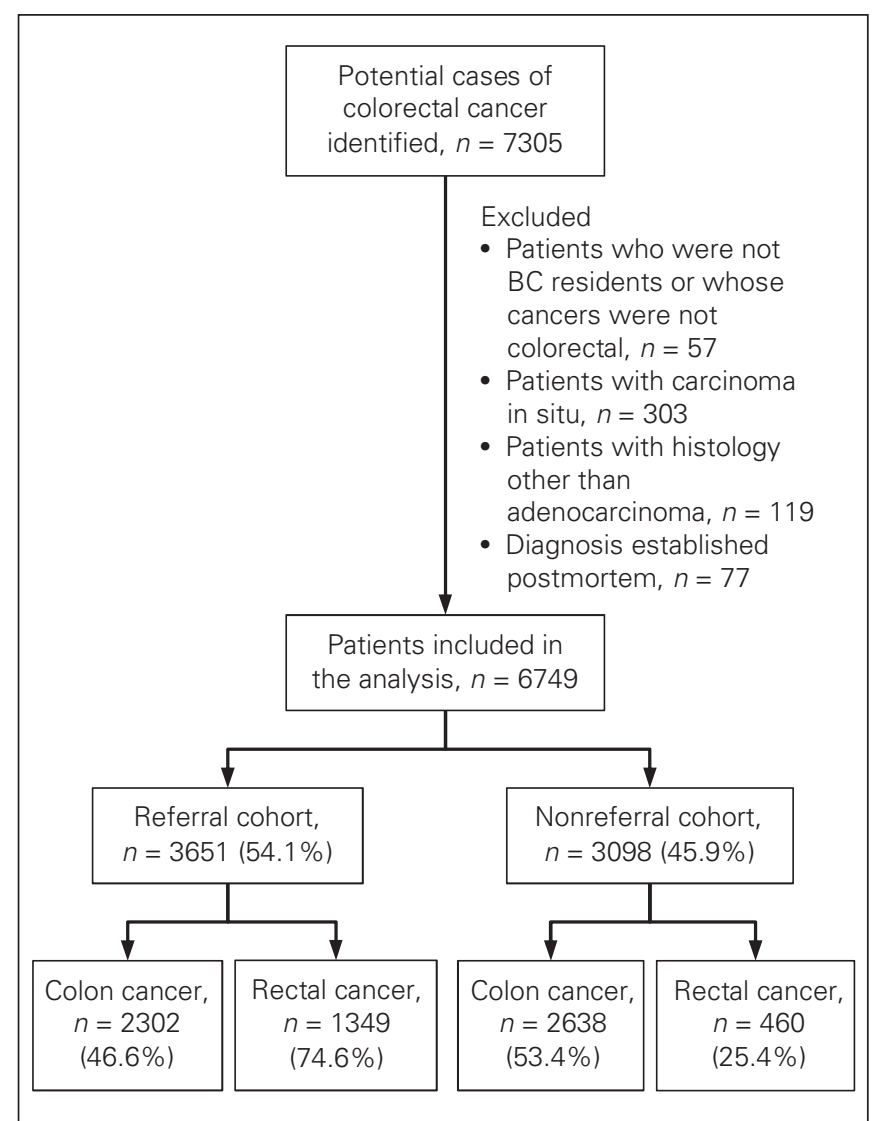

Fig. 1. Study population.

Table 1. Univariate comparison between patients with colon cancer in the nonreferral cohort and the referral cohort

\begin{tabular}{|c|c|c|c|}
\hline \multirow{3}{*}{$\begin{array}{l}\text { Characteristic } \\
\text { Total no. patients with } \\
\text { colon cancer }\end{array}$} & \multicolumn{2}{|c|}{ Cohort; no. (\%) } & \multirow[b]{2}{*}{$p$ value } \\
\hline & Nonreferral & Referral & \\
\hline & $2638(53.4)$ & 2302 (46.6) & \\
\hline Sex & & & 0.017 \\
\hline Female & $1317(55.2)$ & 1071 & \\
\hline Male & $1321(51.8)$ & 1231 & \\
\hline Age, yr & & & $<0.001$ \\
\hline$<40$ & $14(24.1)$ & 44 (75.9) & \\
\hline $40-49$ & 74 (32.7) & $152(67.3)$ & \\
\hline $50-59$ & 261 (39.5) & 400 (60.5) & \\
\hline $60-69$ & $420(40.8)$ & 609 (59.2) & \\
\hline $70-79$ & 888 (53.6) & 770 (46.4) & \\
\hline$\geq 80$ & $981(75.0)$ & $327(25.0)$ & \\
\hline Health authority & & & $<0.001$ \\
\hline Fraser & $854(57.0)$ & $643(43.0)$ & \\
\hline Interior & 462 (48.8) & $485(51.2)$ & \\
\hline Northern & 168 (73.4) & 61 (26.6) & \\
\hline Vancouver Coastal & $682(61.8)$ & $422(38.2)$ & \\
\hline Vancouver Island & $454(39.7)$ & $689(60.3)$ & \\
\hline \multicolumn{4}{|l|}{ Year } \\
\hline 2002 & 903 (55.9) & 712 (44.1) & \\
\hline 2003 & 841 (51.4) & 796 (48.6) & \\
\hline 2004 & $894(53.0)$ & $794(47.0)$ & \\
\hline
\end{tabular}

compared with $1231(48.2 \%)$ men $(p=0.017)$. With increasing age, the likelihood of referral to the BCCA decreased; 44 (75.9\%) patients younger than 40 years were included in the referred cohort compared with 327 (25.0\%) of octogenarians $(p<0.001)$. Referral rates ranged from 61 $(26.6 \%)$ to $689(60.3 \%)$ based on geographic location within the province $(p<0.001)$. The percentage of patients referred to the BCCA increased from 2002 to 2003; a similar increase was not observed between 2003 and 2004.

The univariate analysis for patients with rectal cancer showed significant differences between cohorts with respect to age and regional health authority (Table 2 ). There was no difference in rates of referral by sex $(p=0.23)$. In this group, 855 (75.5\%) men and 494 (73.0\%) women with rectal cancer were included in the referred cohort. With respect to age, a similar trend to that seen among patients with colon cancer emerged; as age increased, rates of referral decreased. Of patients aged younger than 40 years, $24(85.7 \%)$ were included in the CRC database compared with 184 (54.3\%) of patients older than 80 years. Referral rates ranged from $74(67.3 \%)$ to 304 (81.7\%) based on geographic location within the province $(p=0.007)$. The rate of patient inclusion in the CRC database increased from 2002 to 2004.

The results of the logistic regression analysis for patients with colon cancer revealed no significant difference in rate of inclusion in the provincial cancer agency database based on sex, accounting for geographic location and

Table 2. Univariate comparison of patients with rectal cancer in the nonreferral cohort and the referral cohort

\begin{tabular}{|c|c|c|c|}
\hline \multirow[b]{2}{*}{ Characteristic } & \multicolumn{2}{|c|}{ Cohort; no. (\%) } & \multirow[b]{2}{*}{$p$ value } \\
\hline & Nonreferral cohort & Referral cohort & \\
\hline $\begin{array}{l}\text { Total no. patients with } \\
\text { rectal cancer }\end{array}$ & 460 (25.4) & 1349 (74.6) & \\
\hline Sex & & & 0.23 \\
\hline Female & $183(27.0)$ & $494(73.0)$ & \\
\hline Male & 277 (24.5) & 855 (75.5) & \\
\hline Age, yr & & & $<0.001$ \\
\hline$<40$ & $4(14.3)$ & $24(85.7)$ & \\
\hline $40-49$ & 21 (15.9) & $111(84.1)$ & \\
\hline $50-59$ & $42(14.2)$ & $254(85.8)$ & \\
\hline $60-69$ & $86(17.8)$ & $396(82.2)$ & \\
\hline $70-79$ & $152(28.6)$ & $380(71.4)$ & \\
\hline$\geq 80$ & $155(45.7)$ & $184(54.3)$ & \\
\hline Health authority & & & 0.007 \\
\hline Fraser & 139 (26.5) & 385 (73.5) & \\
\hline Interior & $102(26.6)$ & $282(73.4)$ & \\
\hline Northern & 36 (32.7) & 74 (67.3) & \\
\hline Vancouver Coastal & $111(26.7)$ & 304 (73.3) & \\
\hline Vancouver Island & 68 (18.3) & $304(81.7)$ & \\
\hline \multicolumn{4}{|l|}{ Year } \\
\hline 2002 & 181 (29.8) & $426(70.2)$ & \\
\hline 2003 & $143(23.7)$ & $460(76.3)$ & \\
\hline 2004 & $136(22.7)$ & $463(77.3)$ & \\
\hline
\end{tabular}


age $(p=0.33$; Table 3$)$. Variation in rates of referral based on geographic location was noted $(p<0.001)$. The interaction of age at diagnosis and health region was significant, indicating that rates of referral by age were different among the regions.

For patients with rectal cancer, the logistic regression analysis demonstrated no significant difference in rate of referral based on sex while adjusting for health region and age at diagnosis $(p=0.50$; Table 4$)$. For every 5 -year increase in age above 60 years at diagnosis, referral rates were estimated to decrease by $30 \%(p<0.001)$. Accounting for age at diagnosis and sex, significant differences in rates of referral were noted for different geographic regions $(p<0.001)$.

Across each health authority, patients in the referred cohort were more likely to receive chemotherapy than patients in the nonreferred cohort (Table 5). For patients in the nonreferred cohort, the rate of chemotherapy was highest in the Northern Health Authority and the Vancouver Coastal Health Authority for patients with colon and rectal cancer. Figures 2 and 3 demonstrate the variation in chemotherapy rates for patients with colon and rectal cancers, respectively, across regional health authorities in the province of British Columbia.

\section{Discussion}

A major strength of population-based research is the external validity of conclusions based on study results. ${ }^{11}$ The collection of population-based, stage-specific, cancer data requires substantial resources and is currently not available for patients with colorectal cancer within the province of British Columbia. Therefore, much of the research regarding colorectal cancer in British Columbia

Table 3. Logistic regression analysis for patients with colon cancer demonstrating the adjusted effects of each covariate on rate of referral to the BCCA

\begin{tabular}{|c|c|c|}
\hline Effect & $\begin{array}{l}\text { Odds ratio }(95 \% \mathrm{Cl}) \text { for } \\
\text { inclusion in the CRC } \\
\text { database cohort }\end{array}$ & $p$ value \\
\hline Age at diagnosis & & $<0.001$ \\
\hline \multicolumn{3}{|c|}{ Odds of referral for a $5-y r$ increase in age } \\
\hline Northern & $0.86(0.85-8.86)$ & \\
\hline Vancouver Island & $0.70(0.69-0.70)$ & \\
\hline Fraser & $0.77 \quad(0.77-0.77)$ & \\
\hline Vancouver Coastal & $0.77(0.77-0.78)$ & \\
\hline Interior & $0.76(0.76-0.77)$ & \\
\hline Health authority & & $<0.001$ \\
\hline \multicolumn{3}{|c|}{ Odds of referral with mean age $70 \mathrm{yr}$} \\
\hline Northern & 1 & \\
\hline Vancouver Island & $5.880(4.176-8.279)$ & \\
\hline Fraser & $2.304(1.656-3.206)$ & \\
\hline Vancouver Coastal & $1.835(1.309-2.572)$ & \\
\hline Interior & $3.366(2.396-4.729)$ & \\
\hline Sex & $1.061 \quad(0.941-1.197)$ & 0.33 \\
\hline \multicolumn{2}{|c|}{ Interaction between age at diagnosis and health authority } & 0.021 \\
\hline $\begin{array}{l}\mathrm{BCCA}=\mathrm{BC} \text { Cancer Agency; } \mathrm{C} \\
\text { database. }\end{array}$ & $\mathrm{CRC}=$ colorectal cancer ou & \\
\hline
\end{tabular}

has relied on analysis of data collected on patients referred to the BCCA..$^{7-10}$ Referral-based data can be a robust source of information for health care research because of the broad scope of data collected. However, conclusions based exclusively on analysis of referral-based data are subject to health care access bias, whereby referred patients may not be representative of the entire patient population. ${ }^{6,12}$

Our study demonstrates that patients referred to the BCCA, and therefore captured in the CRC database, are systematically different from those patients who are not referred. The results of this study are important in that they demonstrate that patients of advanced age and those living in different regions of the province are not uniformly included in the CRC database. Conclusions based solely on analysis of referral-based data are therefore not necessarily generalizable to the entire population of patients with colorectal cancer in the province.

Previous studies have demonstrated conflicting results in determining the effect of sex on referral to regional cancer centres. ${ }^{13-15}$ In our study, the univariate analysis suggested

Table 4. Logistic regression analysis demonstrating the adjusted effects of each covariate on rate of referral to the BCCA for patients with rectal cancer

\begin{tabular}{|lcc|}
\hline Factor & $\begin{array}{c}\text { Odds ratio (95\% Cl) for } \\
\text { inclusion in the CRC } \\
\text { database cohort }\end{array}$ & p value \\
\hline Increase in 5-yr for age at diagnosis & $0.771(0.733-0.811)$ & $<0.001$ \\
\hline Health authority & 1 & $<0.001$ \\
\hline \multicolumn{1}{|c|}{ Northern } & $2.829(1.722-4.648)$ & $<0.001$ \\
\hline Vancouver Island & $1.601(1.010-2.537)$ & 0.045 \\
\hline Fraser & $1.681(1.048-2.698)$ & 0.031 \\
\hline Vancouver Coastal & $1.652(1.027-2.657)$ & 0.039 \\
\hline \multicolumn{1}{|l|}{ Interior } & $1.082(0.862-1.359)$ & 0.50 \\
\hline Sex & & \\
\hline $\begin{array}{l}\text { BCCA }=\text { BC Cancer Agency; } \mathrm{Cl}=\text { confidence interval; CRC }=\text { colorectal cancer outcomes } \\
\text { database. }\end{array}$ & & \\
\hline
\end{tabular}

Table 5. Chemotherapy treatment by health authority for patients in the referred and nonreferred cohorts

\begin{tabular}{|c|c|c|c|}
\hline \multirow[b]{2}{*}{ Cancer; health authority } & \multicolumn{2}{|c|}{$\begin{array}{c}\text { Cohort; \% who received } \\
\text { chemotherapy }\end{array}$} & \multirow[b]{2}{*}{$p$ value } \\
\hline & BCCR only & CRC database & \\
\hline Colon cancer & & & $<0.001$ \\
\hline Fraser & 15.2 & 59.9 & \\
\hline Interior & 18.2 & 55.9 & \\
\hline Northern & 29.8 & 62.3 & \\
\hline Vancouver Coastal & 27.9 & 62.8 & \\
\hline Vancouver Island & 1.8 & 38.8 & \\
\hline Rectal cancer & & & $<0.001$ \\
\hline Fraser & 5.0 & 54.8 & \\
\hline Interior & 10.9 & 55.3 & \\
\hline Northern & 22.2 & 62.2 & \\
\hline Vancouver Coastal & 18.9 & 55.3 & \\
\hline Vancouver Island & 1.5 & 30.6 & \\
\hline
\end{tabular}


that rates of referral to the BCCA were significantly lower for women with colon cancers than men. However, when these data were corrected for age at diagnosis and health care region, the effect of sex was no longer significant. For patients with rectal cancer, there was no significant difference in rates of capture based on sex in the univariate or logistic regression analysis.

Our study demonstrates that with advanced age, referral to the BCCA decreased. This finding is consistent with previous research showing that patients with advanced age were less likely to be referred to regional cancer centres for multidisciplinary assessment and treatment and that even when referred they were less likely to use available cancer resources than younger patients. ${ }^{13,16}$ As nonreferred patients do not have stage-specific data, it was not possible to determine whether lower rates of referral with advanced age was owing to stage, comorbidity or physician and patient attitudes. Recent research has shown a trend toward more advanced age at initial colorectal cancer diagnosis. ${ }^{16}$ Thus, research based on referral centres may not appropriately inform treatment of elderly patients.

Within the province of British Columbia, regional health authorities have been established to administer health care resources over the large geographic area of the province. In our analysis, we determined that rates of refer-

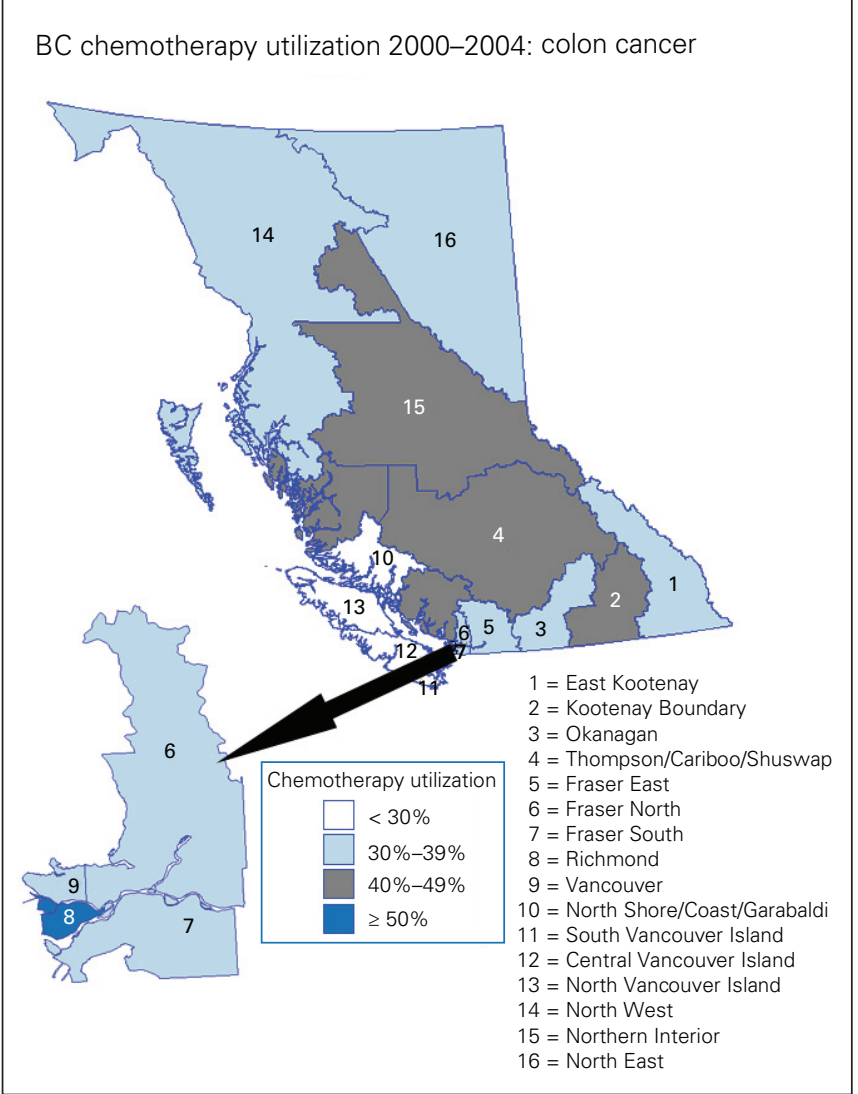

Fig. 2. Geographic variation in chemotherapy rates for patients with colon cancer in the province of British Columbia. ral to the BCCA were significantly different among the province's 5 regional health authorities. Previous research has determined that geographic barriers prevent effective use of available health care resources. ${ }^{16-18}$ Differences in access to cancer care have been shown to vary with rural and urban status. ${ }^{18}$ Previous reports have demonstrated that patients living in rural areas have delayed initiation of chemotherapy and radiation therapy compared with those living in urban areas. ${ }^{19}$ Travel distance invariably contributes to the discrepancy. ${ }^{20}$ Rural status may influence access to cancer screening, cancer care and follow-up. Further research can help quantify the effect of rural status on colorectal cancer outcomes within British Columbia. To serve the vast geographic area of the province, the BCCA has developed satellite sites at regional and community hospitals where patients may access adjuvant therapy. Despite these efforts, the main centres of the BCCA and most of the resources are located in major urban areas. Patients living in more remote regions of the province may be less likely to access these resources and would be less likely to be captured within the CRC database. In addition to potential geographic barriers to assessment at regional cancer centres, the available resources in each health authority may influence rates of BCCA referral and inclusion in the CRC database. Oncologists not affiliated with

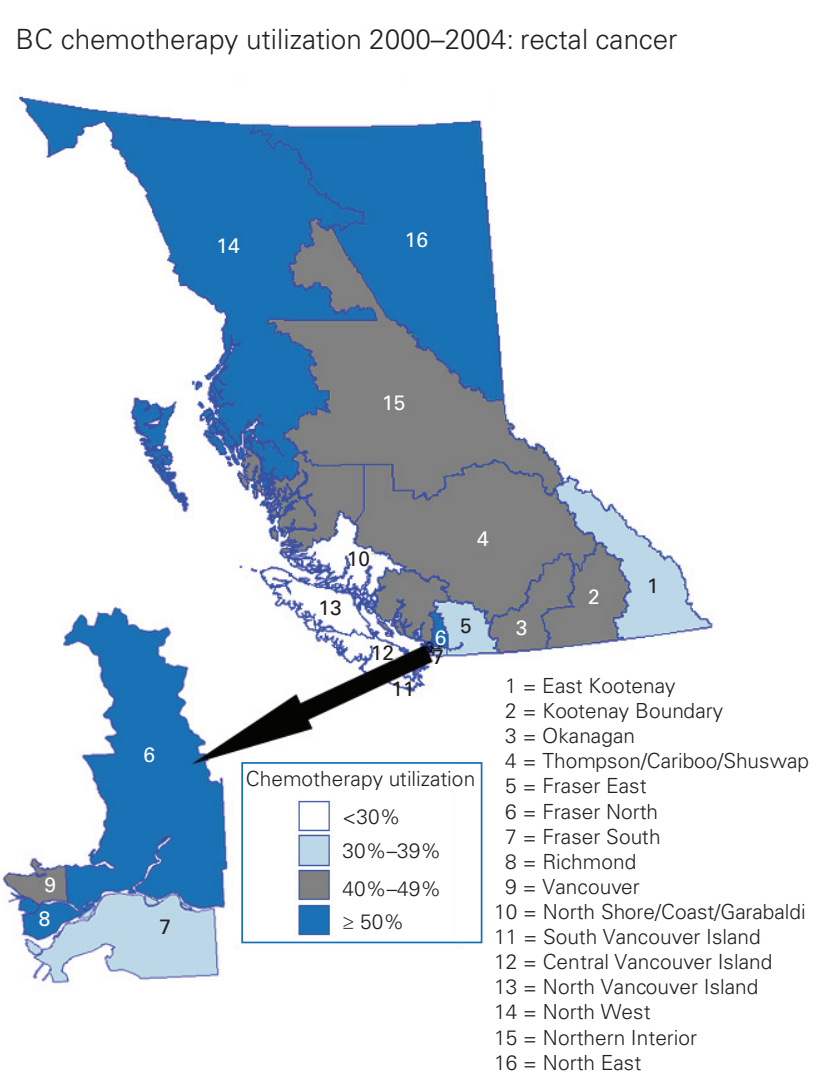

Fig. 3. Geographic variation in chemotherapy rates for patients with rectal cancer in the province of British Columbia. 
the BCCA manage patients with colorectal cancer and prescribe chemotherapy in certain health authorities; these regions may have lower rates of patient inclusion in the CRC database but similar overall therapeutic options for patients with colon cancer. Our results suggest potential geographic influence on referral to regional cancer centres, but further research is required to test this hypothesis.

Previous studies have noted that rates of referral to regional cancer centres have increased over time, possibly related to increased compliance with recommendations for chemo- and radiotherapy for certain stages of colon and rectal cancer, or perhaps owing to educational programs. ${ }^{15,21,22}$ We noted that referral rates varied over the 3year period of our study, but an increased rate of referral was not observed. To determine conclusively whether patient capture into the CRC database has increased over time, analysis over a longer period is required.

As expected, patients referred to the BCCA had higher rates of chemotherapy across all health care authorities in the province. For patients who were not referred to the BCCA, rates of chemotherapy were highest in the Northern Health Authority and the Vancouver Coastal Health Authority. The higher rates of chemotherapy among nonreferred patients within the Northern and Vancouver Coastal Health Authorities may be explained by medical oncologists not affiliated with the BCCA administering adjuvant therapy in these regions. As information on cancer stage is unavailable for the patients included only in the BCCR, it was not possible to determine the effect of cancer stage on chemotherapy rates. The low rates of chemotherapy in the BCCR cohort may be explained by patients having earlystage disease and therefore not requiring chemotherapy. This is unlikely, and previous research has demonstrated that substantial numbers of patients with stage III colon cancer were not referred for chemotherapy. ${ }^{23}$ The inability to collect stage-specific information from the provincial cancer registry limits the ability to interpret the difference in chemotherapy rates between the 2 cohorts. The BCCR is currently involved in the Canadian Partnership Against Cancer National Cancer Staging Initiative, which has a mandate to capture population-based stage information for major cancers, including colorectal cancer, for cases diagnosed from 2010 onward. The implementation of this initiative in British Columbia is planned for late 2011.

\section{Limitations}

The results of this study are subject to potential limitations that must be considered when interpreting our results. Incorrect entry of patient information or miscoding of diagnosis is possible and can lead to misclassification bias. The study was limited to a single Canadian province, and the results may be not be generalizable to other provinces. As stage-specific information is not available for patients in the BCCR cohort, it was not possible to determine the influence of cancer stage on patient inclusion in the CRC database.

\section{Conclusion}

Our results demonstrate that patients included in the referral database are systematically different from the overall population of patients with colorectal cancer in British Columbia with respect to age and geographic location. Patients of advanced age were less likely to be included in the CRC database than younger patients. In addition, geographic variation in rates of inclusion within the CRC database was demonstrated for both colon and rectal cancer. Studies using large data sets at tertiary referral centres, even in places that have consolidated care at these centres, must be interpreted with caution. Our results suggest that health care access bias related to patient age and location within the province influences the validity of the referral database. Expansion of the provincial cancer registry to include stage-specific information as part of the National Staging Initiative will greatly improve the ability to analyze care provided to all patients with colorectal cancer and help with health care resource management and clinical research.

\section{Competing interests: None delcared.}

Contributors: J. Faulds, P.T. Phang and C.J. Brown designed the study. C.E. McGahan and C.J. Brown acquired and analysed the data, which J. Faulds, P.T. Phang and M.J. Raval also analysed. J. Faulds, M.J. Raval and C.J. Brown wrote the article, which C.E. McGahan, P.T. Phang, M.J. Raval and C.J. Brown reviewed. All authors approved the final version for publication.

\section{References}

1. Sewitch MJ, Fournier C, Ciampi A, et al. Adherence to colorectal cancer screening guidelines in Canada. BMC Gastroenterol 2007;7:39.

2. Smiljanic S, Gill S. Patterns of diagnosis for colorectal cancer: screening detected vs. symptomatic presentation. Dis Colon Rectum 2008;51:573-7.

3. Kamangar F, Dores G, Anderson W. Patterns of cancer incidence, mortality, and prevalence across five continents: defining priorities to reduce cancer disparities in different geographic regions of the world. 7 Clin Oncol 2006;24:2137-50.

4. Boyle P, Langman J. ABC of colorectal cancer epidemiology. BMF 2000;321:805-8.

5. Parkin DM. The evolution of the population-based cancer registry. Nat Rev Cancer 2006;6:603-12.

6. Delgado-Rodríguez M, Llorca J. Bias. 7 Epidemiol Community Health 2004;58:635-41.

7. Phang PT, Kennecke H, McGahan C, et al. Predictors of positive radial margin status in a population-based cohort of patients with rectal cancer. Curr Oncol 2008;15:98-103. 
8. Renouf D, Kennecke H, Gill S. Trends in chemotherapy utilization for colorectal cancer. Clin Colorectal Cancer 2008;7:386-9.

9. Pao J, Woods R, Raval M, et al. A population-based study of trends and outcomes in patients with rectal cancer treated with abdominoperineal resection in British Columbia between 2000 and 2006. [abstract] Can 7 Surg 2009;52(Suppl):S45.

10. Ho C, $\mathrm{Ng} \mathrm{K}$, O'Reilly $\mathrm{S}$, et al. Outcomes in elderly patients with advanced colorectal cancer treated with capecitabine: a populationbased analysis. Clin Colorectal Cancer 2005;5:279-82 .

11. Szklo M. Population-based cohort studies. Epidemiol Rev 1998;20:81-90.

12. Palla S, Farella M. External validity: A forgotten issue? 7 Orofac Pain 2009;23:297-8.

13. Etzioni DA, El-Khoueiry A, Beart R. Rates and predictors of chemotherapy use for stage iii colon cancer: a systematic review. Cancer 2008;113:3279-89.

14. Mahoney T, Kuo Y, Topilow D, et al. Stage III colon cancers: why adjuvant chemotherapy is not offered to elderly patients. Arch Surg 2000;135:182-5.

15. Luo R, Giordano S, Freeman J, et al. Referral to medical oncology: a crucial step in the treatment of older patients with stage III colon cancer. Oncologist 2006;11:1025-33.

16. Oliveria SA, Yood M, Campbell U, et al. Treatment and referral pat- terns for colorectal cancer. Med Care 2004;42:901-6.

17. Haas JS, Brawarsky P, Iyer A, et al. Association of area sociodemographic characteristics and capacity for treatment with disparities in colorectal cancer care and mortality. Cancer 2011;117:4267-76.

18. Singh GK, Williams SD, Siahpush M, et al. Socioeconomic, ruralurban, and racial inequalities in US cancer mortality: Part I - All cancers and lung cancer and Part II - colorectal, prostate, breast, and cervical cancers. 7 Cancer Epidemiol 2011;2011:107497.

19. Yu XQ. Socioeconomic disparities in breast cancer survival: relation to stage at diagnosis, treatment and race. BMC Cancer 2009;9:364.

20. Meden T, St. John-Larkin C, Hermes D, et al. MSJAMA. Relationship between travel distance and utilization of breast cancer treatment in rural Northern Michigan. FAMA 2002;287:111.

21. Jessup JM, Stewart A, Greene F, et al. Adjuvant chemotherapy for stage III colon cancer implications of race/ethnicity, age, and differentiation. FAMA 2005;294:2703-11.

22. Cronin DP, Harlan L, Potosky A, et al. Patterns of care for adjuvant therapy in a random population-based sample of patients diagnosed with colorectal cancer. Am f Gastroenterol 2006;101:2308-18.

23. Hill S, Sarfati D, Blakely T, et al. Survival disparities in Indigenous and non-Indigenous New Zealanders with colon cancer: the role of patient comorbidity, treatment and health service factors. 7 Epidemiol Community Health 2010;64:117-23. 